\title{
Measuring Sedentary Behavior During Pregnancy: Comparison Between Self-reported and Objective Measures
}

Miguel Ángel Oviedo-Caro,

Javier Bueno-Antequera,

Diego Munguía-Izquierdo,

Emaildmunizq@upo.es

1 Section of Physical Education and Sports, Department of Sports and Computer Science, University Pablo de Olavide, 41013 Seville, Spain

\section{Abstract}

Objectives To quantify and compare the sedentary time estimated by the Sedentary Behavior Questionnaire (SBQ) and the sedentary time objectively measured by a multi-sensor monitor (SWA) in pregnant women. Methods One hundred eighty-six participants answered the SBQ and wore the SWA at least 7 valid days. The concordance, correlation, agreement and relative activity levels between both measures of sedentary time were examined. Differences of sedentary time between weekday and weekend and between groups stratified by sociodemographic and clinical characteristic were evaluated by oneway analysis of variance. Results Pregnant women were sedentary the $64 \%$ of their waking hours. Television viewing is the most prevalent sedentary behavior. The concordance, correlation, and agreement between SBQ and SWA were weak, yet a significant correlation in weekday and average day sedentary time $(\mathrm{r}=0.23$ and $0.20, P=0.001$ and 0.008 , respectively) was observed. A significant linear trend was found for increasing sedentary time between both methods using a relative activity levels analysis. Conclusions for Practice Pregnant 
women experience high amount of sedentary time, for approximately half of the day. The SBQ shows a low validity and agreement, but strong ability to rank individuals compared with SWA in pregnant women.

\section{Keywords}

Sedentary behavior

Pregnancy

Activity monitor

Self-report

Electronic supplementary material

The online version of this article (https://doi.org/10.1007/s10995-0182473-6) contains supplementary material, which is available to authorized users.

\section{Significance}

This study is the first to quantify and compare the sedentary time estimated by a specific multiple-domain questionnaire and objectively measured by a multi-sensor monitor in pregnant women. The SBQ shows a strong ability to rank individuals in respect to their sedentary activities. The combined use of SBQ and multi-sensor monitor may be appropriate to capture all aspect of sedentary behavior. The quantification of sedentary behaviors allows the exploration of associations between sedentary activities and maternal and fetal health outcomes and the assessment of the effectiveness of intervention strategies promoting health benefits for pregnant women.

AQ1

AQ2

\section{Introduction}

Sedentary behavior can be defined as any waking behavior characterized by an energy expenditure of $\leq 1.5$ metabolic equivalents (METs) while in a sitting or reclining posture (Tremblay et al. 2010). A sedentary lifestyle has been described as a major public health problem 
of the twenty-first century (Blair 2009). Several longitudinal studies have shown the negative health consequences of a sedentary lifestyle (Thorp et al. 2011; Seguin et al. 2014; Pavey et al. 2015) independent of a lack of physical activity (Hamilton et al. 2008).

An increase in sedentary behavior during pregnancy has been associated with adverse perinatal health outcomes including lower birth weight (Both et al. 2010), abnormal glucose tolerance (Oken et al. 2006), increased risk for gestational diabetes mellitus (Oken et al. 2006; Zhang et al. 2006), decreased insulin sensitivity and increased insulin secretion (Gradmark et al. 2011), and excessive gestational weight gain (Jiang et al. 2012). Important strategies to manage healthy weight gain during pregnancy and reduce the prevalence of chronic disease include engaging in regular physical activity and reducing excessive sedentary time (Loprinzi et al. 2013).

It is in the interest of public health to have an objective and selfreported diagnosis of sedentary time because such a diagnosis helps to characterize the patterns of sedentary behavior for developing intervention studies aimed at improving maternal and fetal outcomes. Only one study with a modest sample size $(n=48)$ has objectively measured sedentary behavior during waking hours in pregnant women using multi-sensor monitors, which allow for a direct estimation of sedentary behavior according to METs for multiple and consecutive 24-h periods (Fabio et al. 2015). Other studies have used accelerometers as an objective indirect estimation of sedentary behavior based on the absence of whole-body movement periods during waking hours (Hawkins et al. 2014; Evenson and Wen 2011). However, considering sedentary behavior as the absence of whole-body movement instead of METs may limit the ability to discern between sedentary behavior and inactivity (Sedentary Behaviour Research Network 2012). Some studies have used single-item sitting time questions or physical activity questionnaires (Both et al. 2010; Oken et al. 2006) as self-report measures to quantify sedentary behavior during pregnancy. However, measuring sedentary behavior as the absence of physical activity is inappropriate (Owen et al. 2010), because sedentary behavior is a unique set of behaviors, with a range of potentially unique health consequences, as they influence obesity and other metabolic precursors 
of chronic diseases (Tremblay et al. 2007). Currently, no standardized questionnaires that have been validated in pregnant women exist for the analysis of sedentary behavior. Validated self-report measurements of specific multiple-domains sedentary behaviors, such as the Sedentary Behavior Questionnaire (SBQ) (Rosenberg et al. 2010), can provide useful information to identify high-risk sedentary behavior in largescale studies of pregnant women.

Therefore, we aimed to quantify and compare the sedentary time estimated by the SBQ and the sedentary time objectively measured by a multi-sensor monitor in a relatively large sample of pregnant women, stratified by age, body mass index (BMI), trimester of gestation, parity, occupational status, and educational level. We also compared the sedentary time among the aforementioned groups.

\section{Methods}

At their first prenatal care visit from eleven health clinics in the Sanitary Area of Seville (Spain), eligible participants $(n=273)$ received detailed information about the study aims and protocol and voluntarily gave their written informed consent prior to enrolling in the study. The exclusion criteria included physical illnesses or disabilities that affect normal daily routine and high risk pregnancy (i.e. diabetes or hypertension). Healthy singleton pregnant women aged 18-45 years old were included in the study sample $(n=203)$. Seventeen participants were excluded due to incomplete protocol. The study protocol obtained ethical approval from the Medical Research Ethics Committee of the University Hospital Virgen del Rocio (Seville, Spain) and were performed during two face-to-face sessions, separately by an interval of 8 days.

At the first session, sociodemographic characteristics (age, marital status, educational level and occupational status), clinical characteristics (pre-pregnancy BMI, trimester of gestation and parity), and anthropometric measurements were recorded (Seca 780, Hamburg, Germany), and BMI was calculated using standard procedures (Lohman et al. 1988). In this session, a multi-sensor monitor was placed on the 
left arm of each participant who was asked not to change their habitual lifestyle.

A multi-sensor monitor, Sensewear Mini Armband (BodyMedia Inc., Pittsburgh, PA, USA) (SWA), validated in pregnant women (Smith et al. 2012), was used to objectively assess sedentary behaviors that involved levels of energy expenditure of $\leq 1.5$ METs during waking hours. Monitor includes sensors to measure energy expenditure by monitoring the heat flow from the body, skin temperature, galvanic skin responses and 3-axis accelerometer for motion detection. The multisensor monitor was worn 8 completed days, including 5 weekdays and 2 weekend days, except during water-based activities like swimming or bathing. To be considered a completed day, the multi-sensor monitor was required to be carried for at least $95 \%$ of the entire day $(1.368 \mathrm{~min}$ or longer). To avoid any kind of immediate reactivity that may altered their habitual lifestyle, we removed from the analysis the first day of monitoring.

At the second session, the multi-sensor monitor was removed and the Spanish version of the SBQ (Munguía-Izquierdo et al. 2013) was administered. The SBQ was designed to assess the amount of time spent engaging in 11 behaviors (specified in Table 1). Time reported in each behavior were converted into hours and were summed separately for weekdays and weekend days, and weekly estimates were calculated summing weekday hours multiplied by 5 and weekend hours multiplied by 2 . The SBQ shown acceptable measurement properties in overweight adults (Rosenberg et al. 2010) and Spanish patients with fibromyalgia (Munguía-Izquierdo et al. 2013).

\section{Table 1}

Demographic characteristics of study sample $(\mathrm{n}=186)$

\begin{tabular}{|l|l|}
\hline Variables & $\begin{array}{l}\text { Mean } \pm \text { SD (\% } \\
\text { cases) }\end{array}$ \\
\hline Age (years) & $32.5 \pm 4.4$ \\
\hline a One missing data on prepegnancy BMI & \\
\hline bohree student excluded of occupational status on total sample \\
\hline
\end{tabular}




\begin{tabular}{|c|c|}
\hline Variables & $\begin{array}{l}\text { Mean } \pm \text { SD }(\% \\
\text { cases })\end{array}$ \\
\hline Prepregnancy body mass index (BMI) $\left(\mathrm{kg} / \mathrm{m}^{2}\right)$ & $24.2 \pm 3.7$ \\
\hline $\begin{array}{l}\text { Total objective sedentary time }(\mathrm{h} / \text { day, } \% \text { waking } \\
\text { time) }\end{array}$ & $10.0 \pm 2.1(64 \%)$ \\
\hline Total objective sleep time (h/day) & $6.5 \pm 1.1$ \\
\hline Total self-reported sedentary time (h/day) & $8.7 \pm 3.5$ \\
\hline \multicolumn{2}{|l|}{ Specific self-reported sedentary behaviors (h/day) } \\
\hline Watching television & $2.3 \pm 1.2(99 \%)$ \\
\hline Eating & $1.8 \pm 1.2(100 \%)$ \\
\hline Lying/resting & $1.7 \pm 1.2(99 \%)$ \\
\hline Playing computer/video games & $0.4 \pm 0.7(43 \%)$ \\
\hline Listening to music & $0.1 \pm 0.2(22 \%)$ \\
\hline Talking with others & $0.8 \pm 1.0(94 \%)$ \\
\hline Doing paper/office work & $1.0 \pm 1.6(48 \%)$ \\
\hline Reading & $0.6 \pm 0.9(73 \%)$ \\
\hline Playing a musical instrument & $0.0 \pm 0.2(3 \%)$ \\
\hline Doing arts and crafts & $0.1 \pm 0.4(14 \%)$ \\
\hline \multirow{2}{*}{ Driving/travelling in a motor vehicle } & $0.6 \pm 0.4(97 \%)$ \\
\hline & n $(\%)$ \\
\hline \multicolumn{2}{|l|}{ Ethnicity } \\
\hline Caucasian & $186(100)$ \\
\hline \multicolumn{2}{|l|}{ Trimester of gestation } \\
\hline Second trimester & $109(58.6)$ \\
\hline Third trimester & $77(41.4)$ \\
\hline \multicolumn{2}{|l|}{ Prepregnancy $\mathrm{BMI}^{\mathrm{a}}$} \\
\hline$<25 \mathrm{~kg} / \mathrm{m}^{2}$ & $120(64.9)$ \\
\hline$>25 \mathrm{~kg} / \mathrm{m}^{2}$ & $65(35.1)^{\mathrm{a}}$ \\
\hline \multicolumn{2}{|l|}{ aOOne missing data on prepegnancy BMI } \\
\hline${ }^{\mathrm{b}}$ Three student excluded of occupational status o & sample \\
\hline
\end{tabular}




\begin{tabular}{|l|l|}
\hline Variables & $\begin{array}{l}\text { Mean } \pm \text { SD (\% } \\
\text { cases) }\end{array}$ \\
\hline Marital status & \\
\hline Single without couple & $3(1.6)$ \\
\hline Single with couple & $64(34.4)$ \\
\hline Married & $116(62.4)$ \\
\hline Divorced or separated & $3(1.6)$ \\
\hline Parity & \\
\hline 0 & $103(55.4)$ \\
\hline 1 & $76(40.9)$ \\
\hline$>1$ & $7(3.8)$ \\
\hline Educational level & \\
\hline Non-tertiary & $36(19.3)$ \\
\hline Unfinished studies & $38(20.4)$ \\
\hline Polytechnic school & $23(12.4)$ \\
\hline High school & $91(48.9)$ \\
\hline Tertiary & $31(16.7)$ \\
\hline Medium academic degree & $58(31.2)$ \\
\hline Highly academic degree & \\
\hline Occupational status ${ }^{b}$ & \\
\hline Workers & \\
\hline Non-workers & \\
\hline Unemployed & \\
\hline Sick leave from work & \\
\hline ane missing data on prepegnancy BMI & \\
\hline 'Three student excluded of occupational status on total sample \\
\hline
\end{tabular}

We calculated estimated means for the objective and subjective measures in weekday, weekend, and average day sedentary time across sociodemographic and clinical variables: age, BMI, trimester of 
gestation, parity, occupational status and educational level. Differences among the above mentioned groups were analyzed by a one-way analysis of variance. Differences in sedentary time levels on weekdays versus the weekend were estimated with a one-way analysis of variance for repeated measures. Systematic differences between both measures of sedentary time were calculated using paired t-tests. Concordance between both measures was examined using concordance correlation coefficients (Lin 1989). Pearson correlation coefficients were used as additional information to form comparisons with previous validity studies of sedentary behavior questionnaires. The agreement between both measures of sedentary time was assessed using Bland-Altmant plots (Bland and Altman 1986), including the 95\% levels of agreement. The association between the difference and the magnitude of the measurement was examined using regression analysis. We tested the significance of the differences between methods against zero using a one-sample t-test. To assess relative activity levels, we used the Jonckheere-Terpstra test to evaluate whether the tertile groups of SBQ total sedentary time ranked activity from the objective measurement in an anticipated graded order. A receiver operating characteristic curve was constructed to analyze the validity of the SBQ in predicting $\geq$ $8 \mathrm{~h} /$ day and $\geq 11 \mathrm{~h} /$ day of sedentary behaviors, which are associated with high health risks (Seguin et al. 2014; Pavey et al. 2015). We determined the areas under the curve (AUC) and 95\% confident intervals, and the specificity and sensitivity of the SBQ.

Floor or ceiling effects were calculated from the percentage of participants showing the highest $(24 \mathrm{~h} /$ day $)$ or lowest $(0 \mathrm{~h} /$ day $)$ value in average day sedentary time on the SBQ (Terwee et al. 2007). We used parametric statistics because of the large sample size; however, some of the study variables were non-normally distributed. We repeated the analyses using nonparametric statistics, and the results did not substantially change. Data were analyzed using SPSS package version 20.0 for windows (IBM Corporation) with statistical significance set at $\mathrm{P}<0.050$.

AQ3

\section{Results}


The one hundred eighty-six participants who were included in the analysis provided written consent, wore the SWA for seven valid days, and completed the SBQ (response rate: 74\%). The characteristics of the sample are shown in Table 1. No floor/ceiling effects were presented for the average sedentary time of SBQ $(2 \%$ ceiling effect and $0 \%$ floor effect).

Participants reported an average of $8.7 \pm 3.5 \mathrm{~h}$ of sedentary behaviors while awake. The highest mean time reported for individual items was for watching television, followed by eating, and lying and resting. The lowest reported time was for playing musical instruments, followed by sitting listening to music, and arts and crafts (Table 1). A total of $35 \%$ of the participants reported watching television for more than $20 \mathrm{~h} /$ week ( $\sim 3 \mathrm{~h}$ /day). Approximately $45 \%$ and $36 \%$ of pregnant women reported watching television during the weekend and weekdays, respectively, for more than $3 \mathrm{~h} /$ day.

Pregnant women spent a mean of $10.0 \pm 2.1 \mathrm{~h} /$ day in objectively measured sedentary behavior, comprising $63.5 \%$ of their waking time. This proportion of time was slightly higher on weekdays than on weekends $(P=0.326)$. The subgroups with more time spent in objectively measured sedentary behavior were pregnant women with BMI $>25 \mathrm{~kg} / \mathrm{m}^{2}(10.7 \mathrm{~h} /$ day, $68.2 \%$ of waking time $)$, tertiary education $(10.6 \mathrm{~h} /$ day, $66.1 \%$ of waking time) and women in their third trimester ( $10.5 \mathrm{~h} /$ day, $65.9 \%$ of waking time). The subgroups with less time spent in sedentary behavior were younger pregnant women $(9.3 \mathrm{~h} /$ day, $60.3 \%$ of waking time) and women with BMI $<25 \mathrm{~kg} / \mathrm{m}^{2}(9.7 \mathrm{~h} /$ day, $61.0 \%$ of waking time) (Table 2).

AQ4

\section{Table 2}

Descriptive sedentary time data from the SBQ and SWA by age, BMI, and trim educational level in pregnant women 


\begin{tabular}{|c|c|c|c|c|c|c|}
\hline \multirow[b]{2}{*}{ Participants } & \multicolumn{3}{|c|}{$\begin{array}{l}\text { Weekdays sedentary time } \\
\text { (h/day) }\end{array}$} & \multicolumn{3}{|c|}{$\begin{array}{l}\text { Weekend sedentary time } \\
\text { (h/day) }\end{array}$} \\
\hline & $\begin{array}{l}\text { Estimated } \\
\text { (SWA) }\end{array}$ & $\begin{array}{l}\text { Self- } \\
\text { reported } \\
\text { (SBQ) }\end{array}$ & $\begin{array}{l}\text { P value } \\
\text { between } \\
\text { methods }\end{array}$ & $\begin{array}{l}\text { Estimated } \\
\text { (SWA) }\end{array}$ & $\begin{array}{l}\text { Self- } \\
\text { reported } \\
(\mathrm{SBQ})\end{array}$ & $\begin{array}{l}P_{\text {T }} \\
\text { be } 1 \\
\text { me }\end{array}$ \\
\hline All $(n=186)$ & $10.1(2.3)$ & $8.8(3.9)$ & $<0.001$ & $9.9(2.4)$ & $8.7(3.6)$ & $<\mathrm{C}$ \\
\hline \multicolumn{7}{|l|}{ Age (years) } \\
\hline $\begin{array}{l}20-30(n= \\
47)\end{array}$ & $9.3(2.3)$ & $8.7(4.3)$ & 0.442 & $9.4(2.6)$ & $8.6(3.6)$ & 0.2 \\
\hline $\begin{array}{l}31-44(n= \\
139)\end{array}$ & $10.4(2.2)$ & $8.8(3.7)$ & $<0.001$ & $10.1(2.3)$ & $8.8(3.6)$ & $<\mathrm{C}$ \\
\hline $\begin{array}{l}\mathrm{P} \text { value } \\
\text { between } \\
\text { groups }\end{array}$ & 0.003 & 0.983 & & 0.068 & 0.686 & \\
\hline \multicolumn{7}{|l|}{ BMI $\left(\mathrm{kg} / \mathrm{m}^{2}\right)$} \\
\hline $\begin{array}{l}<25(\mathrm{n}= \\
120)\end{array}$ & $9.7(2.2)$ & $8.5(3.6)$ & $<0.001$ & $9.7(2.4)$ & $8.4(3.4)$ & $0 . C$ \\
\hline$\underset{65)}{\geq 25(n=}$ & $10.8(2.2)$ & $9.3(4.2)$ & 0.012 & $10.5(2.2)$ & $9.3(3.8)$ & $0 . C$ \\
\hline $\begin{array}{l}\mathrm{P} \text { value } \\
\text { between } \\
\text { groups }\end{array}$ & 0.002 & 0.149 & & 0.021 & 0.108 & \\
\hline \multicolumn{7}{|l|}{ Trimester } \\
\hline $\begin{array}{l}\text { Second }(\mathrm{n}= \\
109)\end{array}$ & $9.8(2.4)$ & $8.7(4.0)$ & 0.006 & $9.6(2.4)$ & $8.3(3.4)$ & $0 . C$ \\
\hline $\begin{array}{l}\text { Third }(\mathrm{n}= \\
77)\end{array}$ & $10.5(1.9)$ & $8.9(3.7)$ & $<0.001$ & $10.4(2.4)$ & $9.4(3.7)$ & $0 . C$ \\
\hline $\begin{array}{l}\mathrm{P} \text { value } \\
\text { between } \\
\text { groups }\end{array}$ & 0.022 & 0.708 & & 0.022 & 0.040 & \\
\hline \multicolumn{7}{|l|}{ Parity } \\
\hline $0(n=103)$ & $10.3(2.3)$ & $9.5(4.0)$ & 0.061 & $10.1(2.4)$ & $9.0(3.3)$ & $0 . C$ \\
\hline$>1(n=83)$ & $9.9(2.2)$ & $7.8(3.5)$ & $<0.001$ & $9.8(2.4)$ & $8.4(3.9)$ & $0 . C$ \\
\hline $\begin{array}{l}\mathrm{P} \text { value } \\
\text { between } \\
\text { groups }\end{array}$ & 0.212 & 0.004 & & 0.411 & 0.290 & \\
\hline \multicolumn{7}{|c|}{ Values are mean (SD). The difference of SBQ versus SWA is shown using a pa } \\
\hline$B M I$ body ma & index & & & & & \\
\hline
\end{tabular}




\begin{tabular}{|c|c|c|c|c|c|c|}
\hline \multirow{2}{*}{ Participants } & \multicolumn{3}{|c|}{$\begin{array}{l}\text { Weekdays sedentary time } \\
\text { (h/day) }\end{array}$} & \multicolumn{3}{|c|}{$\begin{array}{l}\text { Weekend sedentary time } \\
\text { (h/day) }\end{array}$} \\
\hline & $\begin{array}{l}\text { Estimated } \\
\text { (SWA) }\end{array}$ & $\begin{array}{l}\text { Self- } \\
\text { reported } \\
(\mathrm{SBQ})\end{array}$ & $\begin{array}{l}P \text { value } \\
\text { between } \\
\text { methods }\end{array}$ & $\begin{array}{l}\text { Estimated } \\
\text { (SWA) }\end{array}$ & $\begin{array}{l}\text { Self- } \\
\text { reported } \\
(\mathrm{SBQ})\end{array}$ & $\begin{array}{l}\text { P r } \\
\text { be } 1 \\
\text { me }\end{array}$ \\
\hline \multicolumn{7}{|c|}{ Occupational status } \\
\hline $\begin{array}{l}\text { Workers }(\mathrm{n} \\
=91)\end{array}$ & $10.2(2.3)$ & $9.1(4.1)$ & 0.015 & $9.9(2.5)$ & $8.5(3.3)$ & $0 . C$ \\
\hline $\begin{array}{l}\text { Non- } \\
\text { workers }(\mathrm{n}= \\
92)\end{array}$ & $10.0(2.2)$ & $8.4(3.6)$ & $<0.001$ & $10.0(2.3)$ & $9.0(3.8)$ & $0 . \mathrm{C}$ \\
\hline $\begin{array}{l}\mathrm{P} \text { value } \\
\text { between } \\
\text { groups }\end{array}$ & 0.570 & 0.236 & & 0.656 & 0.349 & \\
\hline \multicolumn{7}{|c|}{ Educational level } \\
\hline $\begin{array}{l}\text { Non-tertiary } \\
(\mathrm{n}=97)\end{array}$ & $9.5(2.2)$ & $8.2(3.8)$ & 0.003 & $9.7(2.4)$ & $8.5(3.7)$ & $0 . \mathrm{C}$ \\
\hline $\begin{array}{l}\text { Tertiary }(\mathrm{n} \\
=89)\end{array}$ & $10.7(2.2)$ & $9.3(3.8)$ & 0.001 & $10.2(2.3)$ & $9.0(3.4)$ & $0 . \mathrm{C}$ \\
\hline $\begin{array}{l}\mathrm{P} \text { value } \\
\text { between } \\
\text { groups }\end{array}$ & 0.000 & 0.057 & & 0.124 & 0.445 & \\
\hline
\end{tabular}

Values are mean (SD). The difference of SBQ versus SWA is shown using a pa $B M I$ body mass index

Table 2 summarizes sedentary behavior levels, according to the SBQ and SWA, stratified by age, BMI, trimester of gestation, parity, occupational, and educational level. The SBQ presented significantly lower sedentary time compared with the SWA across all stratified groups, except the younger age subgroup ( $<30$ years). No differences between weekday and weekend sedentary time were found across all stratified subgroups, except for women with tertiary education who presented higher sedentary time during weekdays than weekends using the SWA $(P=0.030)$. The subgroups of age $>30$ years, BMI $>$ $25 \mathrm{~kg} / \mathrm{m}^{2}$, third trimester of pregnancy, and tertiary education presented significantly higher sedentary time using the objective measure (SWA) to measure sedentary time in an average day $(P=0.001-0.014)$ 
compared with their respective counterparts. Only nulliparous pregnant women reported significantly higher average day sedentary time than parous pregnant women using the SBQ $(P=0.010)$.

Compared to the SWA, the SBQ underestimated by $12-13 \%(1.2$ $-1.3 \mathrm{~h} /$ day) the weekday, weekend, and average day sedentary time. The difference in weekday, weekend, and average day sedentary time between the two methods was significant $(P<0.001$ for all). A low but significant correlation was observed between self-reported (SBQ) and objective (SWA) weekday sedentary time and average day sedentary time ( $\mathrm{r}=0.23$ and $0.20, P=0.001$ and 0.008 , respectively), whereas no correlation was found for weekend sedentary time $(\mathrm{r}=0.12, P=0.103)$ (Table 3).

\section{Table 3}

Comparison of total weekday, weekend, and average day sedentary time between trimester of gestation, parity, occupational and educational level in pregnant wome

\begin{tabular}{|c|c|c|c|c|c|c|c|}
\hline \multirow[b]{2}{*}{ Participants } & \multicolumn{4}{|c|}{ Weekday sedentary time } & \multicolumn{3}{|c|}{ Weekend sedentary time } \\
\hline & $\begin{array}{l}\text { DM } \\
\text { (SD) } \\
\text { (h/day) }\end{array}$ & $\mathbf{C C C}$ & Pearson & $\mathbf{P}_{\text {Pearson }}$ & $\begin{array}{l}\text { DM } \\
\text { (SD) } \\
\text { (h/day) }\end{array}$ & $\mathbf{C C C}$ & Pearsor \\
\hline $\operatorname{All}(\mathrm{n}=186)$ & $\begin{array}{l}-1.33 \\
(3.99)\end{array}$ & 0.19 & 0.23 & 0.001 & $\begin{array}{l}-1.20 \\
(4.07)\end{array}$ & 0.10 & 0.12 \\
\hline \multicolumn{8}{|l|}{ Age (years) } \\
\hline $\begin{array}{l}20-30(n= \\
47)\end{array}$ & $\begin{array}{l}-0.52 \\
(4.57)^{*}\end{array}$ & 0.17 & 0.17 & 0.260 & $\begin{array}{l}-0.83 \\
(4.46)^{*}\end{array}$ & 0.01 & 0.01 \\
\hline $\begin{array}{l}31-44(\mathrm{n}= \\
139)\end{array}$ & $\begin{array}{l}-1.60 \\
(3.74)\end{array}$ & 0.21 & 0.27 & 0.001 & $\begin{array}{l}-1.32 \\
(3.93)\end{array}$ & 0.13 & 0.16 \\
\hline \multicolumn{8}{|l|}{ BMI $\left(\mathrm{kg} / \mathrm{m}^{2}\right)$} \\
\hline $\begin{array}{l}<25 \\
120)\end{array}(\mathrm{n}=$ & $\begin{array}{l}-1.26 \\
(3.71)\end{array}$ & 0.22 & 0.27 & 0.003 & $\begin{array}{l}-1.22 \\
(4.13)\end{array}$ & 0.04 & 0.04 \\
\hline$\underset{65)}{\geq 25}(\mathrm{n}=$ & $\begin{array}{l}-1.45 \\
(4.51)\end{array}$ & 0.09 & 0.12 & 0.357 & $\begin{array}{l}-1.18 \\
(4.0)\end{array}$ & 0.17 & 0.21 \\
\hline
\end{tabular}

* Mean difference not significantly different from zero using a one-sample t-tes $B M I$ body mass index, $D M$ difference mean between methods, $S D$ standard dev coefficient, Pearson Pearson correlation coefficient, $P_{\text {Pearson }} P$ value for Pearsor 


\begin{tabular}{|c|c|c|c|c|c|c|c|}
\hline \multirow[b]{2}{*}{ Participants } & \multicolumn{4}{|c|}{ Weekday sedentary time } & \multicolumn{3}{|c|}{ Weekend sedentary time } \\
\hline & $\begin{array}{l}\text { DM } \\
\text { (SD) } \\
\text { (h/day) }\end{array}$ & $\mathbf{C C C}$ & Pearson & $\mathbf{P}_{\text {Pearson }}$ & $\begin{array}{l}\text { DM } \\
\text { (SD) } \\
\text { (h/day) }\end{array}$ & $\mathbf{C C C}$ & Pearsor \\
\hline \multicolumn{8}{|l|}{ Trimester } \\
\hline $\begin{array}{l}\text { Second }(\mathrm{n}= \\
109)\end{array}$ & $\begin{array}{l}-1.10 \\
(4.10)\end{array}$ & 0.21 & 0.25 & 0.009 & $\begin{array}{l}-1.31 \\
(3.95)\end{array}$ & 0.10 & 0.11 \\
\hline $\begin{array}{l}\text { Third }(\mathrm{n}= \\
\text { 77) }\end{array}$ & $\begin{array}{l}-1.65 \\
(3.82)\end{array}$ & 0.14 & 0.20 & 0.085 & $\begin{array}{l}-1.03 \\
(4.24)\end{array}$ & 0.07 & 0.08 \\
\hline \multicolumn{8}{|l|}{ Parity } \\
\hline $0(\mathrm{n}=103)$ & $\begin{array}{l}-0.79 \\
(4.23)\end{array}$ & 0.14 & 0.17 & 0.090 & $\begin{array}{l}-1.01 \\
(4.12)^{*}\end{array}$ & 0.00 & 0.00 \\
\hline$>1(\mathrm{n}=83)$ & $\begin{array}{l}-2.00 \\
(3.57)\end{array}$ & 0.21 & 0.29 & 0.007 & $\begin{array}{l}-1.35 \\
(4.02)\end{array}$ & 0.20 & 0.24 \\
\hline
\end{tabular}

Occupational status

\begin{tabular}{|l|l|l|l|l|l|l|l|}
\hline $\begin{array}{l}\text { Workers }(\mathrm{n} \\
\mathbf{9} 9)\end{array}$ & $\begin{array}{l}-1.13 \\
(4.36)\end{array}$ & 0.14 & 0.17 & 0.105 & $\begin{array}{l}-1.38 \\
(3.95)\end{array}$ & 0.08 & 0.10 \\
\hline $\begin{array}{l}\text { Non- } \\
\text { Workers }(\mathrm{n}=\end{array}$ & $\begin{array}{l}\text { 92) } \\
\text { (3.59) }\end{array}$ & 0.24 & 0.31 & 0.003 & $\begin{array}{l}-1.04 \\
(4.22)\end{array}$ & 0.12 & 0.14 \\
\hline
\end{tabular}

Educational level

\begin{tabular}{|l|l|l|l|l|l|l|l|}
\hline $\begin{array}{c}\text { Non-tertiary } \\
(\mathrm{n}=97)\end{array}$ & $\begin{array}{l}-1.28 \\
(4.16)\end{array}$ & 0.11 & 0.14 & 0.183 & $\begin{array}{l}-1.13 \\
(4.44)\end{array}$ & 0.02 & 0.02 \\
\hline $\begin{array}{c}\text { Tertiary }(\mathrm{n} \\
=89)\end{array}$ & $\begin{array}{l}-1.38 \\
(3.81)\end{array}$ & 0.22 & 0.28 & 0.007 & $\begin{array}{l}-1.27 \\
(3.64)\end{array}$ & 0.20 & 0.24 \\
\hline
\end{tabular}

* Mean difference not significantly different from zero using a one-sample t-tes $B M I$ body mass index, $D M$ difference mean between methods, $S D$ standard dev coefficient, Pearson Pearson correlation coefficient, $P_{P e a r s o n} P$ value for Pearsor

\section{$<$}

Focusing on groups stratified by sociodemographic and clinical characteristics, the differences between the two methods in weekday, weekend, and average day sedentary time was significant among all subgroups $(P<0.050)$, except the younger age subgroup and during the weekday for the nulliparous subgroup. The subgroups of parous pregnant women, BMI $<25 \mathrm{~kg} / \mathrm{m}^{2}$, second trimester of pregnancy, nonworkers, and tertiary education presented slightly stronger correlations 
between SBQ and SWA measurements compared with their respective counterparts (Table 3 ).

The Bland-Altman plots and the wide limits of agreement between the SBQ and SWA measurements for the weekday $(6.0,-8.6)$, weekend $(6.5,-9.1)$, and average day sedentary time $(6.8,-9.2)$ are shown in Supplemental Fig. 1. No significant association was found between the difference and the magnitude of both methods for the weekday, weekend, and average day sedentary time $(P>0.050)$. Analysis of the receiver operating characteristic curve identified the SBQ as a poor predictor of the proportion of patients achieving more than 8 and $11 \mathrm{~h} /$ day of sedentary activities, showing high sensitivity ( $88 \%$ true positive) but low specificity ( $21 \%$ true negative) for $8 \mathrm{~h} /$ day, and low sensitivity ( $40 \%$ true positive) but high specificity ( $68 \%$ true negative) for $11 \mathrm{~h} /$ day. The assessment of relative activity levels presented a significant linear trend for increasing total sedentary time based on SWA data across tertiles of sedentary time based on SBQ scores $(P=$ $0.009)$.

\section{Discussion}

This study is the first to quantify and compare the sedentary time estimated by a multiple-domain questionnaire and objectively measured by a multi-sensor monitor in pregnant women. The findings suggest adequate operational qualities for the SBQ but a low validity and agreement when the self-reported sedentary time measured by the SBQ was compared with the objectively measured sedentary time by the SWA in a convenient sample of low-risk pregnant women.

Our pregnant women spent the $64 \%$ of their waking hours in objectively measured sedentary behavior. Our results are slightly lower than the $76 \%$ of time spent in sedentary behavior found by the one study among pregnant women that used the same objective measurement monitor to assess sedentary time according to METs (Fabio et al. 2015). Similar findings were found in a study that used the same measurement instrument in patients with fibromyalgia (Munguía-Izquierdo et al. 2013). Contrary, the non-pregnant adult population has been reported to spend approximately $55-60 \%$ of their waking hours in sedentary 
behavior (Matthews et al. 2008). Consequently, pregnant women appear to represent a population that engages in high levels of sedentary behavior. The SBQ provides information about the pattern of specific sedentary behaviors suitable for analyzing high-risk sedentary behavior during the week in specific contexts. The primary purpose of sedentary time reported by pregnant women was watching television, consistent with findings from other studies in pregnant women (Padmapriya et al. 2015), clinical (Munguía-Izquierdo et al. 2013) and general populations (U.S. Department of Labor. Bureau of Labor Statistics 2016). More than one-third of our participants watched television for more than $20 \mathrm{~h} /$ week, which has been shown to be associated with detrimental health outcomes (Tremblay et al. 2010) and could increase their risk of developing gestational diabetes mellitus (Zhang et al. 2006). In line with other populations (Wood et al. 2015), this excessive television watching was most prevalent on the weekends, with almost half of the pregnant women watching television for more than $3 \mathrm{~h} / \mathrm{day}$.

The SBQ presented lower values of sedentary time compared with the SWA across all stratified groups. Similar to our results, the SBQ (Munguía-Izquierdo et al. 2013; Bond et al. 2013) and other selfreported questionnaires (Scholes et al. 2014) underestimated the average day sedentary time. Contrary, other studies conducted in populations of non-pregnant adults (Busschaert et al. 2015; Wijndaele et al. 2014) overestimated the sedentary time using domain-specific questionnaires. This overestimation may be explained by the use of different questionnaires and/or different objective monitors as criterion measures. Studies using accelerometers with inclinometers, which identify sedentary behavior based on posture allocation, usually show an overestimation of self-reported sedentary time (Busschaert et al. 2015; Wijndaele et al. 2014). While studies using multi-sensor monitors (SWA), which identify sedentary behavior according to METs, usually show an underestimate of self-reported sedentary time (MunguíaIzquierdo et al. 2013; Bond et al. 2013). The use of accelerometers with inclinometer or multi-sensor monitors as criterion measure may produce measurement discrepancies due to possible misclassification of sedentary time because they are unable to differentiate between time sleeping and awake, and between postures (i.e., sitting), respectively. 
Further studies using both tools simultaneously are likely to provide interesting data to validate sedentary behavior questionnaires.

The validity of the SBQ was better for weekdays than for weekend days, suggesting that weekend sedentary time may not be suitable as the sole measure of sedentary behaviors. These findings concur with those of other studies in the adult population (Busschaert et al. 2015) and may be explained by less structured daily activities during weekend days compared to weekdays, making it more difficult to recall weekend sedentary time. Both the subjective and objective measures did not show differences between weekend and weekday sedentary time, except for women with tertiary education who presented higher sedentary time during weekdays than weekends using the SWA. This reduction of sedentary time during weekends is consistent with findings from previous study in non-pregnant women (Ruiz et al. 2013) and can be partially explained by reduced work-related sitting time, since almost half of women with tertiary education perform sedentary office work.

Very few studies have used SWA monitors as the criterion measure for self-reported measures of sedentary time. One other study that used this criterion measure and this questionnaire in a clinical population of women with fibromyalgia found greater accuracy at the group level, as evidenced by a small mean difference but lower correlation (MunguíaIzquierdo et al. 2013). The weak relations and agreement between objective and subjective methods in the present study could suggest that the SBQ fails to adequately capture sedentary behaviors in low-risk pregnant women. In addition, the results of the specificity and sensitivity analysis suggest that the SBQ poorly discriminated people who surpassed 8 and $11 \mathrm{~h}$ of sedentary activities, characteristics that are associated with high health risks (Seguin et al. 2014; Pavey et al. 2015). Nevertheless, the significant linear trend presented on the assessment of relative activity levels suggests the ability of the SBQ to discriminate relative activity levels, reflecting the true ranking of sedentary time and allowing for the examination of its association with health-related variables during pregnancy. Our results suggest that the use of both tools may be appropriate for capturing all aspects of sedentary behavior, but whether the low correlations in the current study were caused by the nature of the survey questions or the types of referent measure is 
uncertain. The reasons for the low correlations between both methods in pregnant women are unclear and require more studies with additional indicators of validity.

Regarding the stratified groups, the younger subgroup was the only subgroup that presented no significant differences between both methods, indicating, in line with other studies (Ferrari et al. 2007) that younger participants could present fewer difficulties when reporting their sedentary behavior levels. The subgroups of pregnant women who were parous and had the lowest age, BMI and trimester of gestation presented slightly stronger correlations and/or smaller mean differences than their counterparts, demonstrating better levels of validity when sedentary time measurements were compared between both methods. This finding might be partially explained by the fact that above mentioned subgroups are more sedentary than their counterparts, thus allowing for a lower margin of error in estimating sedentary time and a lower tendency to reflect social desirability. However, estimates were poor at an individual level, as suggested by wide limits of agreement displaying discrepancies up to approximately $7 \mathrm{~h} /$ day in sedentary time. The SBQ may be most suited for use in large-scale studies than for studies requiring estimates at an individual level, and in subgroups of women with the following characteristics: parous, BMI $<25 \mathrm{~kg} / \mathrm{m}^{2}$, second trimester of pregnancy, non-workers, and tertiary education.

Overall, only the objective measure (SWA) found significant differences in time spent in sedentary behaviors between age, BMI, trimester of gestation, and educational level subgroups. However, both the subjective and objective measures showed that the subgroups of pregnant women who were in their third trimester, had higher BMI, were tertiary educated, were nulliparous, and were over 30 years old were the most sedentary subgroups. This finding highlights that these subgroups may be aware of their high levels of sedentary behaviors. Although pregnant women under 30 years old and with lower BMI presented the lowest sedentary time, both subgroups engaged in sedentary behavior with a duration that exceeded the $60 \%$ of their waking hours. Our findings on the increase in sedentary time with age, BMI, trimester of gestation, and education are consistent with findings from other studies among pregnant women (Fabio et al. 2015; 
Padmapriya et al. 2015), establishing these subgroups at high risk of a sedentary lifestyle.

A first limitation of the study is the inclusion of pregnant women who met eligibility criteria and volunteered to participate, which may result in a self-selection bias. High-risk pregnant women were excluded from the current study. There were no women in their first trimester due to the location of recruitment. The number of participants in the subgroup of overweight and obese women was much lower than the number of participants in the $<25 \mathrm{~kg} / \mathrm{m}^{2}$ subgroup. Since overweight and obese and/or mobility-impaired pregnant women may be at an increased risk for high levels of sedentary time, future research should investigate the measurement properties of sedentary behavior questionnaires in this subgroup. The cross-sectional design of our study precludes the identification of any causal relations. Longitudinal studies are also needed to further understand the predictive value of sedentary behaviors over the course of the pregnancy and to examine the utility of this questionnaire to evaluate change after interventions. The known limitations of nonprobability samples, including their lower representativeness and unknown levels of sampling error, are further limitations.

One strength of the present study was the strict standardization of the methodology used to measure sedentary time. All women had measurements for seven consecutive valid days and reactivity was minimized. The use of SWA may solve the main limitations of accelerometers and inclinometers through heat production measurements, differentiation between sleep and waking time, and placement on the upper arm. The examination of a sedentary behavior questionnaire that included an extensive list of specific sedentary behaviors is another strength. However, a suggestion to further refine the SBQ is to remove or combine certain questions with very low levels of responses (e.g., playing musical instrument) thus minimizing the participant burden and shortening the completion time.

\section{Conclusion}


Pregnant women experience high amount of sedentary time, for approximately half of the day. Pregnant women aged $\geq 30$ years, with a pre-pregnancy BMI $>25 \mathrm{~kg} / \mathrm{m}^{2}$, with tertiary education, and in their third trimester of pregnancy are objectively more sedentary than their respective counterparts. Television viewing is the most prevalent sedentary behavior, with more than one-third of pregnant women watching television for more than $20 \mathrm{~h} /$ week. We find a low validity of self-reported estimates of average day sedentary behavior in pregnant women, but a stronger validity for weekdays than for weekend days. The SBQ shows a strong ability to rank individuals with respect to their sedentary activities. This continuous improvement of self-report measure of sedentary time will be important to obtain a better understanding of the relationship between sedentary behavior and health in pregnant women.

\section{Acknowledgements}

The study was funded by Research Group CTS-948 of University Pablo of Olavide. J.B. is supported by the Spanish Ministry of Education (grant number FPU13/05130). The authors gratefully acknowledge all women for their collaboration. We also acknowledge the health clinic members involved in the recruitment for their effort and great enthusiasm.

\section{Electronic supplementary material}

Below is the link to the electronic supplementary material.

Supplemental Figure 1. Bland and Altman plots of the differences between SWA and SBQ for (a) week days, (b) weekend days, and (c) average day sedentary time. The means of the differences (solid lines) and limits of agreement (dashed lines) within \pm 2 SDs are shown. Abbreviations: SWA (Sensewear) and SBQ (Sedentary Behaviors Questionnaire) (TIF 251 KB)

\section{References}


Blair, S. N. (2009). Physical inactivity: The biggest public health problem of the 21st century. British Journal of Sports Medicine, 43, $1-2$.

Bland, J. M., \& Altman, D. G. (1986). Statistical methods for assessing agreement between two methods of clinical measurement. The Lancet, 327(8476), 307-310.

Bond, D. S., Thomas, J. G., Unick, J. L., et al. (2013). Self-reported and objectively measured sedentary behavior in bariatric surgery candidates. Surgery for Obesity and Related Diseases, 9(1), 123 -128 .

Both, M. I., Overvest, M. A., Wildhagen, M. F., et al. (2010). The association of daily physical activity and birth outcome: A population-based cohort study. European Journal of Epidemiology, 25(6), 421-429.

Busschaert, C., De Bourdeaudhuij, I., Van Holle, V., et al. (2015). Reliability and validity of three questionnaires measuring contextspecific sedentary behaviour and associated correlates in adolescents, adults and older adults. The International Journal of Behavioral Nutrition and Physical Activity, 12(1), 117.

Di Fabio, D. R., Blomme, C. K., Smith, K. M., et al. (2015). Adherence to physical activity guidelines in mid-pregnancy does not reduce sedentary time: An observational study. The International Journal of Behavioral Nutrition and Physical Activity, 12(1), 191.

Evenson, K. R., \& Wen, F. (2011). Prevalence and correlates of objectively measured physical activity and sedentary behavior among US pregnant women. Preventive Medicine, 53(1-2), 39-43.

Ferrari, P., Friedenreich, C., \& Matthews, C. E. (2007). The role of measurement error in estimating levels of physical activity. American Journal of Epidemiology, 166(7), 832-840. 
Gradmark, A., Pomeroy, J., Renstrom, F., et al. (2011). Physical activity, sedentary behaviors, and estimated insulin sensitivity and secretion in pregnant and non-pregnant women. BMC Pregnancy and Childbirth, 11, 44.

Hamilton, M. T., Healy, G. N., Dunstan, D. W., et al. (2008). Too little exercise and too much sitting: Inactivity physiology and the need for new recommendations on sedentary behavior. Current Cardiovascular Risk Reports, 2(4), 292-298.

Hawkins, M., Pekow, P., \& Chasan-Taber, L. (2014). Physical activity, sedentary behavior, and C-reactive protein in pregnancy. Medicine and Science in Sports and Exercise, 46(2), 284-292.

Jiang, H., Qian, X., Li, M., et al. (2012). Can physical activity reduce excessive gestational weight gain? Findings from a Chinese urban pregnant women cohort study. The International Journal of Behavioral Nutrition and Physical Activity, 9, 12.

Lin, L. (1989). A concordance correlation coefficient to evaluate reproducibility. Biometrics, 45(1), 255-268.

Lohman, T. G., Roche, A. F., \& Martorell, R. (1988).

Anthropometric standardization reference manual. Human Kinetics Books, 177, p.3-8.

Loprinzi, P. D., Fitzgerald, E. M., Woekel, E., et al. (2013). Association of physical activity and sedentary behavior with biological markers among U.S. pregnant women. Journal of Women's Health (2002), 22(11), 953-958.

Matthews, C. E., Chen, K. Y., Freedson, P. S., et al. (2008). Amount of time spent in sedentary behaviors in the United States, 2003 -2004. American Journal of Epidemiology, 167(7), 875-881.

Munguía-Izquierdo, D., Segura-Jiménez, V., Camiletti-Moirón, D., et al. (2013). Spanish adaptation and psychometric properties of the 
sedentary behaviour questionnaire for fibromyalgia patients: The alAndalus study. Clinical and Experimental Rheumatology, 31 (Supp1.79), S22-S33.

Oken, E., Ning, Y., Rifas-Shiman, S. L., et al. (2006). Associations of physical activity and inactivity before and during pregnancy with glucose tolerance. Obstetrics and Gynecology, 108(5), 1200-1207.

Owen, N., Healy, G. N., Matthews, C. E., et al. (2010). Too much sitting: The population-health science of sedentary behavior. Exercise and Sports Sciences Reviews, 38(3), 105-113.

Padmapriya, N., Shen, L., Soh, S. E., et al. (2015). Physical activity and sedentary behavior patterns before and during pregnancy in a multi-ethnic sample of Asian women in Singapore. Maternal and Child Health Journal, 19(11), 2523-2535.

Pavey, T. G., Peeters, G. G., \& Brown, W. J. (2015). Sitting-time and 9-year all-cause mortality in older women. British Journal of Sports Medicine, 49(2), 95-99.

Rosenberg, D. E., Norman, G. J., Wagner, N., et al. (2010).

Reliability and validity of the Sedentary Behavior Questionnaire (SBQ) for adults. Journal of Physical Activity \& Health, 7(6), 697 -705 .

Ruiz, J. R., Segura-Jiménez, V., Ortega, F. B., et al. (2013).

Objectively measured sedentary time and physical activity in women with fibromyalgia: A cross-sectional study. BMJ Open, 3(6), 1-10.

Scholes, S., Coombs, N., Pedisic, Z., et al. (2014). Age- and sexspecific criterion validity of the health survey for England physical activity and sedentary behavior assessment questionnaire as compared with accelerometry. American Journal of Epidemiology, 179(12), 1493-1502.

Sedentary Behaviour Research Network. (2012). Letter to the Editor: Standardized use of the terms "sedentary" and "sedentary 
behaviours". Applied Physiology, Nutrition, and Metabolism, 37(3), $540-542$.

Seguin, R., Buchner, D. M., Liu, J., et al. (2014). Sedentary behavior and mortality in older women: The women's health initiative. American Journal of Preventive Medicine, 46(2), 122-135.

Smith, K. M., Lanningham-Foster, L. M., Welk, G. J., et al. (2012). Validity of the SenseWear armband to predict energy expenditure in pregnant women. Medicine and Science in Sports and Exercise, 44 (10), 2001-2008.

Terwee, C. B., Bot, S. D. M., de Boer, M. R., et al. (2007). Quality criteria were proposed for measurement properties of health status questionnaires. Journal of Clinical Epidemiology, 60(1), 34-42.

Thorp, A. A., Owen, N., Neuhaus, M., et al. (2011). Sedentary behaviors and subsequent health outcomes in adults: A systematic review of longitudinal studies, 1996-2011. American Journal of Preventive Medicine, 41(2), 207-215.

Tremblay, M. S., Colley, R. C., Saunders, T. J., et al. (2010). Physiological and health implications of a sedentary lifestyle. Applied Physiology, Nutrition, and Metabolism, 35(6), 725-740.

Tremblay, M. S., Esliger, D. W., Tremblay, A., et al. (2007). Incidental movement, lifestyle-embedded activity and sleep: New frontiers in physical activity assessment. Canadian Journal of Public Health, 98(Supp. 2), S208-S217.

U.S. Department of Labor. Bureau of Labor Statistics. (2016). American time use survey-2015 results. News Release, 16, 1-24.

Wijndaele, K., De Bourdeaudhuij, I., Godino, J. G., et al. (2014). Reliability and validity of a domain-specific last 7-d sedentary time questionnaire. Medicine and Science in Sports and Exercise, 46(6), $1248-1260$. 
Wood, L., Jago, R., Sebire, S. J., et al. (2015). Sedentary time among spouses: A cross-sectional study exploring associations in sedentary time and behaviour in parents of 5 and 6 year old children. $B M C$ Research Notes, 8(1), 787.

Zhang, C., Solomon, C. G., Manson, J. E., et al. (2006). A prospective study of pregravid physical activity and sedentary behaviors in relation to the risk for gestational diabetes mellitus. Archives of Internal Medicine, 166(5), 543-548. 